\title{
METODOLOGIA INVESTIGATIVA NO ENSINO DA CINÉTICA QUÍMICA
}

\section{ANDRÉ ROMERO DA SILVA}

Instituto Federal do Espírito Santo

E-mail: aromero@Ifes.edu.br

\section{MARIA AUXILIADORA VILELA PAIVA}

Instituto Federal do Espírito Santo

E-mail: dora@Ifes.edu.br

\section{RESUMO}

Os processos químicos presentes nas indústrias de transformação, o envelhecimento do nosso organismo, o crescimento das plantas e a geração das chuvas, são exemplos de processos controlados por fatores cinéticos que permeiam nossa rotina diária. Aulas fundamentadas em exemplos abstratos e com excesso de cálculos matemáticos diminuem o interesse dos alunos em aprender este conteúdo, assim como, não contribuem para formar professores conscientes da importância da ciência química e sua relação com a sociedade e com o meio ambiente. Com o intuito de realizar uma intervenção pedagógica no ensino de cinética química, esta pesquisa teve por objetivo avaliar se uma metodologia investigativa propicia aos alunos a habilidade de investigar e refletir sobre fatos observados na disciplina de Cinética Química. A pesquisa desenvolvida com os alunos da Licenciatura em Química de uma Instituição Pública, demonstrou que a metodologia investigativa foi capaz de desenvolver a habilidade de observação e reflexão dos graduandos sobre a ocorrência de uma reação química. No entanto, a ausência dos conceitos matemáticos, incluindo o de derivada, dificultou o desenvolvimento de um procedimento experimento por parte dos alunos, exigindo o replanejamento de ações no laboratório. Verificou-se que a metodologia investigativa favorece a interação e comunicação entre os pares, auxiliando no estabelecimento de uma metodologia experimental a ser aplicada por cada grupo para responder aos questionamentos relativos a reação de tiossulfato em meio ácido. Tal prática trouxe ao ambiente educacional a discussão sobre a geração de resíduo laboratorial, qualificando os alunos a trabalharem com quantidades suficientes de reagentes para se atingir os mesmos resultados que seriam atingidos com grandes quantidades, além de associar a intervenção pedagógica às influências da cinética química junto às questões ambientais.

PALAVRAS-ChAVE:

Formação Do Professor; Metodologia Investigativa; Cinética-Química; Tiossulfato.

\section{INVESTIGATIVE METHODOLOGY IN THE TEACHING OF CHEMICAL KINETIC}

\begin{abstract}
Chemical processes present in the transformation industries, the aging of our organism, the growth of plants and the generation of rains are examples of processes controlled by kinetic factors that permeates our daily routine. However, classes based on abstract example and by excessive
\end{abstract}


mathematical calculations decrease the students' interest in learning about this content, as well as, do not contribute to train teachers to be aware of the importance of chemical science and its relation to society and the environment. In order to make a pedagogical intervention in the teaching of chemical kinetics, this work aimed to evaluating if an investigative methodology to provide for the student the ability to investigate and reflect on facts observed in the discipline of chemical kinetics. The research developed with students of the Licentiate in Chemistry of a Public Institution, showed that the investigate methodology was able to develop the students' ability to observe and reflect on the occurrence of a chemical reaction. However, the absence of mathematical concepts, including that of derivative, made it difficult for students to develop an experimental procedure, requiring the planning of actions in the laboratory. It was verified that the investigative methodology favors the interaction and communication between the pairs, helping in the establishment of an experimental methodology to be applied by each group to answer the questions regarding the reaction of thiosulphate in acid environment. This practice brought to the educational environmental the discussion about the generation of laboratory residue, qualifying the students to work with enough quantities of reagents to achieve the same results that would be reached with large quantities, besides associating the pedagogical intervention to the influences of the chemical kinetics on the environmental issues.

\section{KEYWORDS:}

Teacher Training; Investigative Methodology; Chemical-Kinetic; Thiosulphate.

\section{INTRODUÇÃO}

Estudos de cinética química são considerados muito abstratos e caracterizados por excesso de cálculos matemáticos, fatos que diminuem o interesse dos alunos em aprender sobre este conteúdo. Sabe-se também que conteúdos ministrados ao estudante desconectados da vida diária, não fazem sentido algum, tornando o ensino conteudista e desnecessário. No entanto, vários fatos do cotidiano estão relacionados à cinética química como o processo de envelhecimento dos seres vivos, de oxidação de tintas, de objetos como grades e portões, bem como, no controle de atividades industriais no consumo de reagentes e na formação de produtos. Concordamos com a afirmação de Martorano (2007, p.21), de que a cinética química é:

[...] um conteúdo imprescindível para a formação básica em química do aluno do ensino médio. O conhecimento da cinética química proporciona ao aluno o entendimento da velocidade de uma reação química e dos fatores que a determinam ou a modificam, mas, além disso, leva ao entendimento do mecanismo (ou caminho) de uma reação.

No entanto, a metodologia tradicional usada nos cursos de química no ensino de cinética não contribui para o processo de ensino e aprendizagem dos estudantes. A 
falta de diálogo e interação nas aulas coloca o professor como autoridade máxima que não permite ou estimula a participação dos estudantes, e a pequena ou quase inexistente relação entre professor-aluno são características metodológicas que necessitam ser alteradas nos cotidianos das salas de aula. É notório que em muitos cursos de Licenciatura ainda perdure o ensino centrado nos professores que não estimulam os futuros docentes a se apropriarem de saberes da docência e desenvolverem habilidades importantes para o ensino.

Sendo assim, faz-se necessário que os docentes tenham uma preocupação em propiciar aos alunos ensinamentos que os ajudem a utilizar a ciência de forma conectada às suas realidades, possibilitando ao discente compreender e resolver problemas do seu dia a dia (MARTORANO; MARCONDES, 2009).

Com o intuito de avaliar recursos metodológicos que propiciem aos alunos investigar e perceber a importância da cinética química, de forma que eles possam participar ativamente do processo de ensino e aprendizagem, refletindo sobre os fatos observados e tomando decisões com base em conceitos aprendidos em sala de aula, é que este trabalho propõe o uso de metodologia investigativa no processo de ensino e aprendizagem do conteúdo de cinética química. Nós entendemos que "a perspectiva do ensino com base na investigação possibilita o aprimoramento do raciocínio e das habilidades cognitivas dos alunos, e também a cooperação entre eles, além de possibilitar que compreendam a natureza do trabalho científico" (ZÔMPERO; LABURÚ, 2011, p. 68).

A metodologia investigativa recomendada por Derwey, em 1938, pressupõe que o aluno participe ativamente de sua aprendizagem, sugerindo problemas para serem investigados com base na aplicação dos conhecimentos de ciências aos fenômenos naturais (ZÔMPERO, 2011). Naturalmente, os procedimentos relacionados à investigação científica possibilitam que os alunos desenvolvam várias habilidades, 
como observar fenômenos, anotar informações relevantes, descrever fatos, fazer questionamentos e procurar respostas às perguntas formuladas (BARROW, 2006).

Vislumbrando uma formação de professores de Química com vistas ao ensino, de forma que eles possam vivenciar metodologias investigativas que Ihes auxiliarão no trabalho futuro em sala de aula, é que se optou por desenvolver este trabalho com alunos dos cursos de Licenciatura em Química. Estes alunos cursam uma disciplina intitulada como Química Geral que aborda uma série de conteúdos importantes para a vida profissional de um professor de Química. Entre estes assuntos, destaca-se o relacionado à cinética química.

Neste sentindo, este estudo buscou compreender se a metodologia investigativa utilizada para ministrar o conteúdo de Cinética Química propicia aos alunos do curso superior de Licenciatura em Química o desenvolvimento de habilidades para tomar decisões sobre uma reação química. Isto é, saber verificar quando a reação ocorreu, estabelecendo procedimentos adequados para coletar informações e concluir sobre as características cinéticas de uma reação. Basicamente os alunos trabalharam com a reação do tiossulfato $\left(\mathrm{S}_{2} \mathrm{O}_{3}{ }^{2-}\right)$ com o ácido sulfúrico $\left(\mathrm{H}_{2} \mathrm{SO}_{4}\right)$ produzindo enxofre $(\mathrm{S})$, dióxido de enxofre e água como produtos (Equação 1).

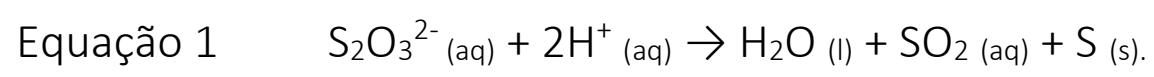

Particularmente, o trabalho usa o estudo da velocidade da reação para identificar e quantificar substâncias importantes presentes no nosso cotidiano. Um exemplo é o tiossulfato $\left(\mathrm{S}_{2} \mathrm{O}_{3}{ }^{2-}\right)$ utilizado como fixador fotográfico, como agente complexante de íons ouro (I) no processo de extração de ouro, e reagente usado para identificar a presença de íons $\mathrm{Al}^{3+}$. Neste sentindo, os alunos foram instigados a identificarem a concentração de $\mathrm{S}_{2} \mathrm{O}_{3}{ }^{2-}$ numa amostra problema com base na reação de formação do enxofre a partir da reação do tiossulfato em meio ácido (MADAM; TULI, 2007), bem como, determinar a Lei de Velocidade da reação de formação do 
enxofre sólido, a partir de conhecimentos adquiridos em sala de aula e sem o fornecimento preliminar de um procedimento experimental.

\subsection{A MetOdologia INVESTIGATIVA}

Ainda que os cursos superiores de áreas tecnológicas apresentem disciplinas que envolvam atividades laboratoriais, muitos destes cursos oferecem disciplinas experimentais baseadas em metodologias tradicionais apoiadas por roteiros do tipo "receita" onde dificilmente estão presentes o raciocínio e o questionamento (DE ANDRADE; DINIZ; CAMPOS, 2011; FERREIRA; HARTWIG; DE OLIVEIRA, 2010).

O parecer CNE/CES 1.303/2001 do Conselho Nacional de Educação sobre as diretrizes curriculares nacionais para os cursos de Química, enfatiza a necessidade de que o professor de Química desperte o interesse científico nos adolescentes, utilizando-se para isto de laboratórios adequados. Infelizmente, há no ensino superior e também no ensino médio, uma prática entre os professores que ministram aulas de laboratório que "experimentos que funcionam, devem ser conservados e mantidos, dentro do rol de atividades a serem desenvolvidas pelos alunos". (DA SILVA; SCHNETZLER, 2005, p. 1123).

Entendemos que não será por meio de metodologias tradicionais baseadas em roteiros pré-estabelecidos e práticas imutáveis que os professores irão adquirir saberes profissionais que propiciem o desenvolvimento de habilidades científicas dos seus alunos. O mesmo ocorre ao separar as ações pedagógicas e estudos metodológicos de ensino das práticas laboratoriais. Este método dominante presente nas grandes universidades e nas pequenas faculdades espalhadas pelo Brasil transforma o aluno em sujeito passivo da aprendizagem, não sendo estimulada sua capacidade de compreensão e estruturação de problemas, muito menos a buscar soluções para os mesmos, inibindo sua criticidade frente aos desafios que uma experimentação possa lhe trazer (DE ANDRADE, 2011). 
Em contraponto com esta prática corroboramos com uma metodologia que siga os passos da metodologia científica a qual prevê que o professor estabeleça um problema disparador aos alunos, de forma que os discentes atuem, ativamente, buscando estratégias de resolução. Sendo assim, os alunos necessitam definir procedimentos a serem feitos no laboratório, e neste sentindo, precisam discutir com antecedência, e em grupo, quais medidas serão tomadas no laboratório para que o experimento possa ser realizado, os dados experimentais possam ser coletados e planilhados, e as informações avaliadas para que se chegue a resolução do problema proposto.

A importância da experimentação está em seu caráter investigativo e pedagógico, auxilia o aluno na formulação de teses, problematização, explicitação, discussão e na elaboração de novos conceitos. Dessa forma, a abordagem experimental trará significação aos conceitos químicos. (SALESSE; BARICATTI 2007, p. 9).

Dessa forma, a metodologia investigativa favorece a associação entre a teoria e a prática por parte dos alunos, possibilitando maior compreensão dos conceitos químicos ministrados em sala de aula e suas aplicações na sociedade. O ensino de química sem experimentação “[...]é apenas um arremedo do ensino, dogmático e sem atrativo, que afasta os alunos do estudo e compromete sua formação como cidadãos [...]" (SALESSE; BARICATTI, 2007, p.10).

Esta metodologia oferece ao aluno a possibilidade de integrar e processar informações oriundas das necessidades e interesses individuais para a adequação ao meio em que vivemos (LUCKESI, 1994). Sendo assim, a interação entre o aluno e o objeto em estudo é fundamental para a assimilação do conhecimento e modificação de estruturas mentais pré-existentes (MIZUKAMI, 200). Portanto, o ensino deve ser baseado em proposição de problemas em que a ideia é aprender fazendo, sendo o trabalho em grupo fundamental para o desenvolvimento do aluno (LUCKESI, 1994). 


\subsection{O ENSINO DE CINÉTICA QUÍMICA}

Considerado a necessidade de associar os conceitos ensinados em cinética química com a vida diária dos alunos que entendemos ser mais interessante abordar assuntos na sala de aula em que a metodologia investigativa possa ser utilizada com a Lei de velocidade, a ordem de reação em relação ao um determinado reagente ou em relação a reação global, o tempo de reação e o tempo de meia-vida. Mais interessante ainda seria se tais conteúdos pudessem ser trabalhados por meio de experimentos em que os alunos pudessem construir, satisfatoriamente, os processos de ensino e aprendizagem. As atividades experimentais despertam um forte interesse entre os alunos pelos conteúdos relacionados às aulas práticas, permitindo que as aulas sejam motivadoras e que a aprendizagem seja colaborativa através da realização de experimentos em equipe e com a colaboração entre as equipes.

A formação de um espírito colaborativo de equipe pressupõe uma contextualização socialmente significativa para a aprendizagem, ponto de vista da problematização (temas socialmente relevantes) como da organização do conhecimento científico (temas epistemologicamente significativos) (GIORDAN, 1999, p. 46).

Somando-se a esta reflexão Schwahn e Oaigen (2008) atentam que a ausência de articulação entre a teoria e a prática no ensino de química e a falta de estrutura dos laboratórios são fatores que afastam professores e alunos das aulas experimentais, o que entendemos ser prejudicial para o processo de ensino-aprendizagem no ensino de ciências. Giordam (1999) alerta para os benefícios da experimentação e como os experimentos de cinética química podem ser fortes aliados para a compreensão da essência da vida.

O uso limitado de experimentos no ensino de química, a deficiência em contextualizar as aulas de ciências em temas de CTS (Ciência, Tecnologia e Sociedade) e a baixa interdisciplinaridade das aulas ministradas pelos professores, têm prejudicado a formação de alunos cidadãos (SOUZA; BORGES, 2013). A 
experimentação investigativa deve despertar um pensamento crítico e reflexivo dos alunos, tornando-os "sujeitos de sua aprendizagem através do modo como levantam hipóteses, discute com os outros colegas e refletem sobre um tema" (SOUZA; BORGES, 2013).

Defendemos assim, uma metodologia investigativa que forme os futuros docentes para atuarem de forma a considerar os conceitos científicos interligados às culturas a eles subjacentes e às questões sociais que estão inseridos, assumindo que “[...] ser professor exige saberes próprios, saberes da profissão. Consideramos assim, a formação do professor como uma cultura específica, processo pelo qual o indivíduoprofessor, torna-se portador e gerador de sentido." (DE OLIVEIRA; PAIVA, 2018, p.11).

Considerando que o conteúdo de cinética química está intimamente relacionado com nossa vida pessoal, na velocidade em que envelhecemos, ou na redução da velocidade de degradação dos alimentos que nós ingerimos, mas também a cinética química envolvida na intoxicação de rios e o solo pela uso excessivo de fertilizantes e agrotóxicos, na ocorrência e o efeito da chuva ácida ou do efeito estufa, entre tantos outros problemas pelas quais o uso indiscriminado e descontrolado das substâncias químicas ocorre sem haver a preocupação com a sociedade e o meio ambiente.

Neste sentindo, o movimento CTSA tem contribuído no que se refere a formação da capacidade de tomada de decisão dos indivíduos frente aos problemas que a cinética química pode trazer a sociedade, mostrando que a ciência não tem um caráter pronto e acabado e que os avanços tecnológicos e suas aplicações estão presentes na vida cotidiana, podendo causar impactos aos cidadãos e ao meio ambiente (LOPES, 2013).

Entendemos ser necessário que os docentes abordem os contextos sociocientíficos, buscando estabelecer as interações entre a ciência, a sociedade e a moralidade, e estimulando a criticidade dos alunos para se envolverem de forma mais 
atuante nas questões de ordem, social, políticas, econômicas e ambientais. (BATISTA, 2014; MARCONDES, 2009). Para que esta consciência social permeie as salas de aula, buscamos uma formação de professores para um ensino no qual a ciência não seja neutra e que a sala de aula seja entendida como um espaço de apropriação do conhecimento.

Com o intuito de aproximar a ciência à realidade da vida dos alunos, buscando associar a importância do conteúdo de cinética química no desenvolvimento das tecnologias que influenciam as rotinas diárias dos estudantes, mas abordando as consequências para o cotidiano da sociedade e o meio ambiente é que se buscou incluir nas aulas preparatórias desta intervenção pedagógica a relação das velocidades das reações geradoras de derivados de enxofre, nitrogênio e carbono junto aos efeitos ambientais da chuva ácida e efeito estufa.

\section{Percurso Metodológico}

Considerando que este trabalho propõe uma nova prática docente frente ao ensino do conteúdo de cinética química por meio de uma metodologia investigativa que torne o ensino aprendizagem mais interessante e significativo aos alunos que optamos por uma pesquisa tipo intervenção pedagógica. Entendemos a intervenção pedagógica como:

[...] investigações que envolvem o planejamento e a implementação de interferências (mudanças, inovações) - destinadas a produzir avanços, melhorias, nos processos de aprendizagem dos sujeitos que delas participam - e a posterior avaliação dos efeitos dessas interferências (DAMIANI, 2013, p. 58).

\subsection{A Prática PedagógICA}

Inicialmente foi realizada uma exposição do experimento a ser realizado, sendo concedido ao aluno a opção de participar do experimento no papel de aluno participante ou não. Destaca-se que todos alunos optaram por participar da intervenção pedagógica e assinaram o Termo de Consentimento Livre e Esclarecido. 
Este trabalho de pesquisa foi aprovado pelo Comitê de Ética em Pesquisa do IFES sob número 86728318.7.0000.5072.

A intervenção pedagógica abordou o conteúdo de Cinética Química que faz parte da ementa obrigatória do curso de Licenciatura em Química dos 21 alunos pertencentes a turma de Química Geral II do IFES campus Aracruz.

A pesquisa foi iniciada pela aplicação de um questionário que buscou identificar o perfil dos licenciandos e seus conhecimentos prévios sobre os conceitos a serem trabalhados nas aulas. Diante das características que devem compreender as atividades de investigação, conforme proposto por Gil Perez e Valdes Castro (1996), como: apresentar a situação problema aos alunos e refletir sobre a relevância das situações-problema apresentadas; elaborar um planejamento da atividade experimental; emitir hipótese a partir da investigação científica; considerar a contextualização do problema aos temas de CTS, e proporcionar momentos para a comunicação do debate das atividades desenvolvidas; é que as seguintes etapas foram realizadas nesta prática (Tabela 1):

Tabela 1: Etapas, metodologias e atividades desenvolvidas pelo professor pesquisador e pelos alunos na pesquisa. Fonte: próprio autor.

\begin{tabular}{|c|l|l|}
\hline Etapa & \multicolumn{1}{|c|}{$\begin{array}{c}\text { Atividades desenvolvidas pelo } \\
\text { professor }\end{array}$} & \multicolumn{1}{c|}{$\begin{array}{c}\text { Atividades desenvolvidas pelos } \\
\text { alunos }\end{array}$} \\
\hline 1 & Ministrar aulas dialogadas & $\begin{array}{l}\text { Participar das aulas abrangendo os } \\
\text { conteúdos de velocidade de reação, } \\
\text { Lei de velocidade e ordem de reação } \\
\text { contextualizados com o efeito estuda } \\
\text { e a chuva ácida }\end{array}$ \\
\hline 2 & $\begin{array}{l}\text { Formar grupos com 3 alunos para } \\
\text { dialogar e elaborar um } \\
\text { procedimento experimental }\end{array}$ & $\begin{array}{l}\text { Preparar metodologia para } \\
\text { determinar a Lei de velocidade da } \\
\text { reação entre o } \mathrm{S}_{2} \mathrm{O}_{3}{ }^{2-} \text { e o } \mathrm{H}_{2} \mathrm{SO}_{4}\end{array}$ \\
\hline
\end{tabular}




\begin{tabular}{|c|l|l|}
\hline 3 & $\begin{array}{l}\text { Supervisionar e observar a execução } \\
\text { da prática pelos alunos, } \\
\text { questionando-os sobre os detalhes } \\
\text { experimentais }\end{array}$ & $\begin{array}{l}\text { Coletar os fatos observados da } \\
\text { reação química para poder responder } \\
\text { aos questionamentos do professor, } \\
\text { bem como, ao questionário que será } \\
\text { anexado ao relatório }\end{array}$ \\
\hline 4 & $\begin{array}{l}\text { Reunir os alunos no laboratório, } \\
\text { após o fim do experimento, para } \\
\text { ressaltar fenômenos ocorridos } \\
\text { durante a prática experimental, bem } \\
\text { como, possíveis falhas que possa ter } \\
\text { ocorrido. }\end{array}$ & $\begin{array}{l}\text { Discutir com seus pares e o professor } \\
\text { sobre os resultados obtidos no } \\
\text { experimento, bem como, os fatos } \\
\text { experimentais observados }\end{array}$ \\
\hline 5 & $\begin{array}{l}\text { Instruir os alunos sobre a preparação } \\
\text { do relatório a ser entregue por cada } \\
\text { grupo }\end{array}$ & $\begin{array}{l}\text { Preparar um relatório contendo } \\
\text { introdução, objetivo, metodologia, } \\
\text { resultados, discussões e as respostas } \\
\text { às questões entregues no laboratório }\end{array}$ \\
\hline
\end{tabular}

Durante a intervenção pedagógica, observações foram realizadas pelo professor pesquisador e anotações dos diálogos e interações dos alunos foram coletados por meio de filmagens e gravações para a produção de informações essenciais para a avaliação da intervenção pedagógica.

\subsection{A ReaÇão QUímica Utilizada na InTERVEnção PedAGógICA}

A prática experimental aplicada aos alunos envolveu a reação entre o tiossulfato e o ácido sulfúrico, havendo a formação de dióxido de enxofre, água e enxofre sólido (MADAM; TULI, 2007):

$$
\mathrm{S}_{2} \mathrm{O}_{3}{ }^{2-}{ }_{(\mathrm{aq})}+2 \mathrm{H}^{+}{ }_{(\mathrm{aq})} \rightarrow \mathrm{H}_{2} \mathrm{O}_{(\mathrm{l})}+\mathrm{SO}_{2} \text { (aq) }+\mathrm{S}_{(\mathrm{s})}
$$

Cabe destacar que em termos de periculosidade, o produto da reação (enxofre sólido) não é explosivo, muito menos seus reagentes (ácido sulfúrico diluído e tiossulfato de sódio). A concentração do ácido sulfúrico (0,05 mol/L) é bem diluída, a fim de minimizar possíveis queimaduras, caso haja contato da solução com a pele. Entretanto, deve-se ressaltar que as quantidades dos reagentes a serem utilizadas foram pequenas o bastante para que os experimentos pudessem ser realizados em 
tubos de ensaios de $10 \mathrm{~mL}$, minimizando possíveis contaminações da pele e dos olhos.

Os alunos trabalharam apenas com $50 \mathrm{~mL}$ de cada reagente para poderem elaborar seus procedimentos experimentais. Tal situação foi imposta aos alunos para que eles pudessem organizar a parte experimental de forma a gerar a menor quantidade possível de resíduo químico, o qual foi armazenado em frasco adequado para ser tratado e eliminado pelo técnico de laboratório.

Para o experimento, foram fornecidas aos alunos $50 \mathrm{~mL}$ de duas soluções de concentrações conhecidas ( $\mathrm{Na}_{2} \mathrm{~S}_{2} \mathrm{O}_{3}$ 0,2 $\mathrm{mol} / \mathrm{L} \mathrm{e} \mathrm{H}_{2} \mathrm{SO}_{4} 0,05 \mathrm{~mol} / \mathrm{L}$ ), uma bureta de 50 $\mathrm{mL}, 10$ tubos de ensaio de $10 \mathrm{~mL}$, uma estante para tubo de ensaio e um cronômetro por grupo. A partir destas soluções e tubos de ensaio, os alunos puderam fazer diluições destas soluções e monitorar o tempo necessário para a ocorrência da reação. Para evitar que metodologias equivocadas pudessem ser utilizadas pelos alunos, intervenções foram realizadas pelo professor pesquisador durante a discussão do grupo para a elaboração do procedimento experimental.

A formação do enxofre sólido pode ser monitorada em função do tempo, sendo que sua produção pode ser identificada pela turvação da mistura reacional. Portanto, a turvação é um indício do avanço da reação. Entretanto, foi fornecido aos estudantes apenas a informação que eles trabalhariam com a reação entre o $\mathrm{S}_{2} \mathrm{O}_{3}{ }^{2-}$ e $\circ \mathrm{H}_{2} \mathrm{SO}_{4}$, sendo necessária a pesquisa dos produtos a serem obtidos nesta reação, bem como, o estabelecimento dos parâmetros visuais que seriam adotados para o estudo cinético da reação. A partir do monitoramento do tempo, respostas poderiam ser obtidas para se determinar a ordem da reação, a lei de velocidade da reação, bem como, construir uma curva de calibração em função do tempo para identificar a concentração de uma solução desconhecida de $\mathrm{S}_{2} \mathrm{O}_{3}{ }^{2-}$. 


\subsection{MÉtodo Utilizado na AVALIAÇÃo do Trabalho EXeCUTAdo pelos Alunos}

Foi previsto na pesquisa uma etapa de avaliação dos alunos. Esta avaliação foi feita in loco, no transcorrer da evolução dos experimentos por parte dos discentes, fazendo questionamentos aos estudantes do grupo para compreender o grau de interação dos alunos com o experimento realizado, bem como, o nível de compreensão e entendimento do que estavam fazendo no laboratório. As interpretações dos alunos ao problema posto para ser resolvido foram também consideradas, com base nas respostas das autoavaliações, com o intuito de apoiar a avaliação em múltiplos critérios que sejam significativos à aprendizagem do aluno. Sendo assim, a prática pedagógica foi avaliada por 3 instrumentos: um relatório que foi confeccionado por grupo de alunos, a participação dos integrantes do grupo e a autoavaliação dos discentes. O relatório preparado por cada grupo de alunos apresentou respostas relativas à cinco questões que só poderiam ser respondidas a partir da realização dos experimentos: 1) Escreva a reação entre o $\mathrm{S}_{2} \mathrm{O}_{3}{ }^{2-}$ e a solução de $\mathrm{H}_{2} \mathrm{SO}_{4}$ e os resultados desta reação. Qual o fato utilizado pelo seu grupo para ter certeza que a reação ocorreu? Qual produto foi gerado na reação estudada que causou as alterações perceptíveis na mistura?; 2) Determine a concentração da amostra desconhecida de $\mathrm{S}_{2} \mathrm{O}_{3}{ }^{2-}$. Com base nos experimentos realizados, desenvolva uma metodologia para se determinar esta concentração; 3) A lei de velocidade para esta reação, provavelmente, tem a forma $v=k\left[\mathrm{~S}_{2} \mathrm{O}_{3}{ }^{2-}\right]^{m}\left[\mathrm{H}^{+}\right]^{n}$. Determine a ordem da reação em relação ao $\mathrm{S}_{2} \mathrm{O}_{3}{ }^{2-}$; 4) Calcule a meia-vida do $\mathrm{S}_{2} \mathrm{O}_{3}{ }^{2-}$. Se o tempo de meia vida do $\mathrm{S}_{2} \mathrm{O}_{3}{ }^{2-}$ fosse menor que o valor determinado, que consequências haveria sobre a determinação do valor de tiossulfato na amostra problema; 5) Qual é a ordem da reação em relação aos $\mathrm{H}_{2} \mathrm{SO}_{4}$ e qual é a lei de velocidade desta reação?

O professor pesquisador, de tempos em tempos, passou pelos grupos para monitorar o desenvolvimento das atividades desenvolvidas, auxiliando os estudantes na resolução de dúvidas, mas sem responder às questões exigidas no relatório. Com 
relação a autoavaliação, todos os alunos responderam a um questionário contendo as seguintes perguntas: a) Você se preparou para a realização deste experimento? ( ) sim ( ) não; b) Você conseguiu realizar o experimento até o final, respondendo a todos os questionamentos previstos para o relatório? ( ) sim ( ) não; c) Você apresentou alguma dificuldade na elaboração do procedimento experimental? ( ) sim. Qual? ( ) não; d) Você apresentou alguma dificuldade na execução do experimento? ( ) sim. Qual? ( ) não; e) As interações e discussões em grupo foram decisivas para a realização da investigação e construção dos conceitos trabalhados? ( ) Sim ( ) Não ( ) Em parte; f) Como você avaliaria o empenho do grupo nas tarefas propostas? ( ) Excelente ( ) Ótimo ( ) Bom ( ) Satisfatório ( ) Péssimo; g) Se fosse possível valorar seu empenho, no preparo anterior a realização do experimento, na execução das atividades no laboratório e na confecção do relatório, qual seria o seu aproveitamento? ( ) Excelente ( ) Ótimo ( ) Bom ( ) Satisfatório ( ) Péssimo; h) Você conseguiu compreender a importância do conteúdo de cinética química para a sua vida cotidiana? ( ) sim ( ) não; i) Cite um exemplo de aplicação da cinética química presente na sua vida cotidiana, excluindo os exemplos citados em sala e no laboratório, contemplando os temas CTS.

Como critério de avaliação das atividades desenvolvidas pelos alunos foi utilizada a seguinte distribuição de pontos para os instrumentos avaliativos: 50 pontos para o relatório, 25 pontos para a abordagem realizada pelo professor no laboratório e 25 pontos para a autoavaliação.

\section{RESUltAdOS E DisCUSSÃO}

\subsection{Diagnóstico INICIAL do CONHECIMENTO dos AlunOs REFERENTE a CONCEITOS IMPORTANTES NO}

\section{APRendizAdo de CInÉtICA Química}

O interesse em realizar um diagnóstico inicial foi o de identificar dificuldades que os estudantes teriam em relação aos conteúdos básicos de química, necessários para um aprendizado satisfatório do aluno em cinética química, bem como, orientar as aulas 
a serem ministradas no sentindo de sanar possíveis dificuldades dos estudantes relacionadas aos conceitos que seriam trabalhados na disciplina. Neste sentindo, entende-se que o diagnóstico inicial, funcionou como uma avaliação e foi importante para o sucesso da intervenção pedagógica, estando de acordo com as colocações de Luckesi (2005, p. 43) de que "Para não ser autoritária e conservadora, a avaliação terá de ser diagnóstica, ou seja, deverá ser o instrumento dialético do avanço, terá de ser o instrumento do reconhecimento dos caminhos percorridos e da identificação dos caminhos a serem perseguidos".

O questionário inicial aplicado aos alunos foi constituído por três questões que permitiram identificar se os estudantes tinham conhecimento prévio de estequiometria, se apresentavam raciocínio lógico matemático relativo a cálculos de potenciação e se possuíam conhecimentos básicos de cinética química, de forma que foi possível se obter um diagnóstico inicial da turma (Tabela 2). Os resultados mostraram que $45 \%$ dos alunos envolvidos neste trabalho possuíam sólido conhecimento referente ao conteúdo de estequiometria, enquanto que 55\% não possuíam conhecimentos significativos. Estes resultados sugerem uma deficiência no aprendizado dos alunos da Licenciatura em seu $2^{\circ}$ período referente a conteúdos primordiais para os licenciados em química, mesmo após pouco tempo de terem cursado a disciplina de Química Geral I em que foi ministrado este assunto. Os resultados também revelaram que o conhecimento básico matemático estava ausente em 95\% dos alunos, sendo que apenas 5\% deles mostraram possuí-lo para poder entender a metodologia usada na identificação da ordem de uma reação. Esta deficiência em conteúdo de matemática é comum de ser observada em sala de aula, e pode estar vinculada às estratégias inadequadas no ensino da matemática como o desenvolvimento exacerbado da álgebra, mas sem a aplicação em resoluções de problemas (FERREIRA; BRUMATTI, 2009). 
Diante desta situação, este conhecimento básico matemático foi novamente abordado em sala de aula, durante a apresentação do conteúdo relacionado à ordem total e parcial de uma reação, no sentindo de garantir as competências necessárias aos alunos para que eles pudessem participar desta pesquisa com condições de atingir os objetivos propostos. Por fim, o resultado mostrou que apenas $5 \%$ dos alunos possuíam um conhecimento básico de cinética química, fato já esperado, pois é um assunto pouco explorado no ensino médio da maioria das escolas. Sendo assim, as aulas ministradas aos alunos do curso de licenciatura foram elaboradas de forma que os estudantes pudessem ter o conhecimento necessário sobre cinética química, e assim, pudessem desenvolver as metodologias a serem aplicadas dentro do laboratório.

Tabela 2: Diagnóstico inicial dos alunos referente ao conhecimento em estequiometria, raciocínio lógico (potenciação) e conhecimento básico de cinética. Fonte: próprio autor.

\begin{tabular}{|l|c|c|}
\hline \multicolumn{1}{|c|}{ Assunto relacionado a questão } & Nota & Quantidade de alunos /\% \\
\hline \multirow{4}{*}{ Estequiometria } & 100 & 25 \\
\cline { 2 - 3 } & 75 & 20 \\
\cline { 2 - 3 } & 10 & 10 \\
\cline { 2 - 3 } & 0 & 45 \\
\hline Raciocínio lógico matemático & 55,5 & 5 \\
\cline { 2 - 3 } $\begin{array}{l}\text { relativo a potenciação } \\
\text { Conhecimentos básicos de cinética } \\
\text { química }\end{array}$ & 0 & 95 \\
\cline { 2 - 3 } & 25 & 5 \\
\hline
\end{tabular}

\subsection{DesenVolvimento das Aulas sobre Cinética Química}

Durante as aulas buscou-se mostrar a importância do aprendizado da cinética química, e a sua influência sobre assuntos voltados ao movimento Ciência, Tecnologia, Sociedade e Ambiente (CTSA). A importância da cinética química junto ao efeito estufa, à chuva ácida, bem como, ao ciclo de envelhecimento do ser humano associado à sua rotina diária, foram discutidos em sala de aula. Foi constatada uma participação significativa dos alunos quando estes assuntos foram abordados conectados à realidade dos estudantes e associados ao conhecimento científico, proporcionando aos alunos "discutir sobre possíveis impactos gerados por esses produtos da ciência 
tanto na sociedade como no meio ambiente" (LOPES, 2013, p. 9). No entanto, esta participação não foi observada quando houve necessidade de se trabalhar a matemática em conjunto com operações de potenciação, equações exponenciais e álgebra linear. As principais dúvidas foram de operações básicas matemáticas, como em divisões de fração, mudança de sinal e cálculos envolvendo potenciação e logaritmo. Ao serem questionados se haviam visto estes tópicos em sala na disciplina de Fundamentos da Matemática, a grande maioria disse não se lembrar. Entretanto, poucos alunos afirmaram que estes assuntos foram sim abordados na disciplina mencionada, evidenciando as deficiências de aprendizado dos alunos relativos aos conteúdos básicos da matemática. Este fato é preocupante pois muitos assuntos da cinética são dependentes de operações usando conceitos logarítmico, equações exponenciais, mudança de sinais e conceitos básicos da álgebra, fato que compromete o aprendizado deste conteúdo de química geral.

São realidades presentes em sala de aula que demonstram a forte necessidade de conectarmos o ensino de matemática às demais áreas da ciência, e vice-versa, com o objetivo de favorecer o desenvolvimento de habilidades dos nossos futuros docentes de química. Entendemos que "uma determinada área das ciências, por si só, não pode ser considerada a única detentora da verdade, pois a mesma, em seu processo de estruturação, necessita de outros ramos das ciências para que possa assumir um caráter mais inclusivo e pedagógico do conhecimento interdisciplinar e dar sustentáculo e validação aos saberes" (RODRIGUES; RIBEIRO, 2018, p. 62).

Outro fato importante a ser relatado é que o conteúdo de cinética envolve o estudo de reações cuja modificação da concentração de reagentes ou produtos pode ocorrer segundo uma dependência exponencial de 1aㅡ ordem ou de 2aㅡ ordem (ATKINS; JONES, 2018). Estes estudos dependem da resolução de equações diferenciais simples que só são possíveis de serem resolvidas com o pleno domínio do conteúdo da disciplina de Cálculo I. Infelizmente, os alunos da Licenciatura em química cursam a 
disciplina de Química Geral II concomitante com a disciplina de Cálculo I, e de forma geral, o conteúdo de cinética é sempre ministrado no início da disciplina, portanto, antes que os alunos possam adquirir competências para a resolução das equações diferenciais.

Uma possibilidade para reduzir este impacto seria a realização de um planejamento conjunto de ambos os docentes das duas disciplinas mencionadas, com o intuito de minimizar as dificuldades dos alunos com relação a este assunto de química geral. A sugestão está de acordo com a perspectiva da previsão e da intencionalidade evocada por Padilha (2001, p. 63) de que "Planejar, em sentido amplo, é um processo que visa dar respostas a um problema, através do estabelecimento de fins e meios que apontem para a sua superação, para atingir objetivos antes previstos, pensando e prevendo necessariamente o futuro, mas sem desconsiderar as condições do presente e as experiências do passado [...]"

Para este trabalho não foi exigido dos alunos a resolução de equações diferenciais e, durante às aulas, procurou-se usar as equações já resolvidas para diminuir a dificuldade durante a apresentação das reações de 1a e 2a ordens. Mesmo assim, a ausência de conhecimento dos conteúdos de derivada e integral, presentes na maioria dos cálculos cinéticos, dificultou aos alunos associarem a necessidade de identificar a ocorrência da reação em um curto espaço de tempo.

No experimento que os alunos realizaram, a grande importância está no início da reação já que não há como usar apenas a visão para identificar quando uma reação acabou. Sendo assim, nesta intervenção, houve necessidade de se identificar a ocorrência da reação em seu início, e neste caso, os conceitos de derivada ajudariam no entendimento da determinação da velocidade inicial de uma reação.

Quanto mais tempo o aluno demorar para identificar a ocorrência da reação, maior será o erro na identificação da velocidade inicial da reação. A questão é que se 
a reação se processar por muito tempo, a concentração do reagente consumido passa a ser muito significativa, e assim, a variação da concentração do reagente também, de forma que a velocidade da reação passa a não ser possível de ser identificada, por não se conseguir quantificar a concentração final do reagente ou mesmo do produto (enxofre sólido). Entretanto, se a identificação da ocorrência da reação for feita logo no seu início (através da mínima turvação reacional), será possível terminar a velocidade inicial da reação, já que a variação da concentração de reagentes será mínima, e portanto, poderá se considerar algumas aproximações para a identificação do tempo necessário para a ocorrência da velocidade inicial da reação:

$$
\begin{aligned}
& \mathrm{S}_{2} \mathrm{O}_{3}{ }^{2-}{ }_{(\mathrm{aq})}+2 \mathrm{H}^{+}{ }_{\text {(aq) }} \rightarrow \mathrm{H}_{2} \mathrm{O}_{(\mathrm{ll})}+\mathrm{SO}_{2}(\mathrm{aq})+\mathrm{S}_{(\mathrm{s})} . \\
& \text { velocidade }=-\frac{\mathrm{d}\left[\mathrm{S}_{2} \mathrm{O}_{3}^{2-}\right]}{\mathrm{dt}}=-\frac{1}{2} \frac{\mathrm{d}\left[\mathrm{H}^{+}\right]}{\mathrm{dt}} \\
& \text { velocidade }=\frac{\mathrm{n}_{\mathrm{o}}\left(\mathrm{S}_{2} \mathrm{O}_{3}^{2-}\right)-\mathrm{n}_{\text {consumido }}\left(\mathrm{S}_{2} \mathrm{O}_{3}^{2-}\right)}{\text { volume } \mathrm{x} \text { tempo }} \\
& \text { velocidade inicial }=\frac{\mathrm{n}_{\mathrm{o}}\left(\mathrm{S}_{2} \mathrm{O}_{3}^{2-}\right)}{\text { volume } \mathrm{x} \text { tempo }}
\end{aligned}
$$

pois $\mathrm{n}_{\text {consumido }}\left(\mathrm{S}_{2} \mathrm{O}_{3}{ }^{2-}\right)$ será tão pequeno que poderá ser considerado desprezível.

Considerando que no início da reação, o número de mols de tiossulfato consumido é muito pequeno, pode-se então calcular a velocidade da reação com base apenas na concentração inicial do reagente, neste caso, o tiossulfato, mantendo-se a concentração do ácido constante. Este entendimento foi complicado para os alunos identificarem sozinhos, muito em razão da dificuldade de compreender sobre a identificação da velocidade inicial de uma reação. Mas intervenções foram feitas durante as aulas com o intuito de que os alunos pudessem entender sobre o fato relatado, e então, todos passassem a compreender como poderiam monitorar a 
velocidade inicial de uma reação, ainda que não se tivesse afirmado qual seria o parâmetro visual para tal fim.

As dificuldades dos estudantes em estabelecer proporções matemáticas, como foi identificado na avaliação inicial, foram identificadas no momento em que foi apresentado em sala a relação entre a velocidade global da reação e as velocidades parciais de consumo dos reagentes e de formação dos produtos, sendo a velocidade global dependente das quantidades estequiométricas da reação. Esses fatos sugerem a necessidade de alteração da prática docente, buscando formas interdisciplinares para o ensino de Ciências, em que novos caminhos pedagógicos e metodológicos possam ser trilhados em conjunto com outras áreas da ciência (RIBEIRO, 2014).

\subsection{Fatos Observados com os Alunos DuRANte as Aulas Teóricas}

Estudos tem sugerido que a utilização da experimentação no uso de química pode proporcionar ao estudante uma reflexão crítica do mundo, permitindo o desenvolvimento do seu cognitivo a partir dos conteúdos abordados em sala de aula (MALDANER; SCHNETZLER, 1998).

Ao trabalhar com os alunos durante o experimento pudemos observar avanços como também diversas dificuldades, entre essas a de estabelecer uma metodologia de ação. As dificuldades apresentadas pelos alunos ao estabelecer uma metodologia capaz de responder as questões colocadas como desafio, foram todas elas relacionadas à determinação da ordem da reação em relação a cada reagente e do tempo de meia vida, ao estabelecimento da lei de velocidade da reação envolvida, e à determinação da concentração desconhecida de uma amostra de $\mathrm{S}_{2} \mathrm{O}_{3}{ }^{2-}$. Além disso, os alunos foram incentivados a desenvolver uma metodologia em que fosse gerada pequenas quantidades de resíduos químicos. Para isso, volumes fixos de reagentes foram fornecidos aos grupos de alunos, os quais tiveram que se planejar para poderem fazer toda a parte experimental, sem receber quantidades adicionais de reagentes. 
Nesta etapa da intervenção, foi possível identificar muitos erros de raciocínio estequiométrico para fins de determinação da concentração inicial dos reagentes, por deficiência na compreensão dos alunos sobre os cálculos de diluição de solução.

Os resultados do aproveitamento dos alunos (Tabela 3) revelaram que alguns grupos se empenharam na confecção de um relatório que fosse constituído por introdução, objetivo, parte experimental, resultados e discussão, conclusão e referencial bibliográfico, bem como, contivesse respostas às questões apresentadas no início dos experimentos. Apenas $28,5 \%$ dos grupos de alunos apresentaram aproveitamento igual ou superior a $60 \%$ da pontuação máxima possível para o relatório, enquanto 42,8\% apresentaram aproveitamento inferior a 45\% da pontuação máxima. Infelizmente, estes alunos com menor pontuação apresentaram relatórios inconsistentes, com resultados irregulares, sem discussão adequada aceitável e com deficiência às respostas solicitadas no início da intervenção pedagógica realizada no laboratório.

No questionário de autoavaliação foi constatado que poucos alunos se posicionaram com um aproveitamento excelente $(5,3 \%)$, sendo que a grande maioria $(57,8 \%)$ optou por afirmar que seu desempenho no preparo e realização do experimento foi bom. Apenas 31,6\% afirmou que seu desempenho foi ótimo e 5,7\% apontou um desempenho satisfatório. Todos os alunos consideraram que se prepararam para os experimentos e $84,2 \%$ afirmaram não apresentar qualquer dificuldade na elaboração do procedimento experimental ou na execução dos experimentos. Entretanto, vários grupos possuíram muitas dúvidas na realização do experimento, mesmo após 6 aulas realizadas para o estabelecimento de metodologia a ser aplicada no laboratório.

Todos os alunos afirmaram ter compreendido a importância do conteúdo de cinética química para a sua vida cotidiana, no entanto nenhum aluno conseguiu citar 
um exemplo de aplicação da cinética química contemplando os temas CTSA. Provavelmente, o ensino tradicional de ciências acrescido da menção de conteúdos CTSA, não sejam suficientes para o pleno entendimento da importância da cinética química para a sociedade e o meio ambiente. Talvez a incorporação sistemática do conteúdo de CTSA ao conteúdo programático possa fortalecer e dinamizar os conceitos cinéticos e suas influências sobre a vida da sociedade como proposto por Ainkehead (2006).

Tabela 3: Aproveitamento dos alunos participantes da intervenção pedagógica. Fonte: próprio autor.

\begin{tabular}{|c|c|c|c|c|c|}
\hline \multirow{4}{*}{$\begin{array}{c}\text { Grupo } \\
1\end{array}$} & \multirow{4}{*}{$\begin{array}{c}\begin{array}{c}\text { Pontuação } \\
\text { Relatório } \\
\text { (máximo } 50 \\
\text { pontos) }\end{array} \\
21\end{array}$} & \multirow{4}{*}{$\begin{array}{c}\text { Pontuação Participação } \\
\text { (máximo } 25 \text { pontos) } \\
25\end{array}$} & \multicolumn{2}{|c|}{$\begin{array}{c}\text { Pontuação } \\
\text { autoavaliação } \\
\text { (máximo } 25 \text { pontos) }\end{array}$} & \multirow{2}{*}{$\begin{array}{c}\text { Pontuação total } \\
\text { (máximo } 100 \\
\text { pontos) }\end{array}$} \\
\hline & & & Aluno 1 & 23 & \\
\hline & & & Aluno 2 & 23 & 69 \\
\hline & & & Aluno 3 & 23 & 69 \\
\hline \multirow{3}{*}{2} & \multirow{3}{*}{30,5} & \multirow{3}{*}{25} & Aluno 1 & 22 & 77,5 \\
\hline & & & Aluno 2 & 15 & 70,5 \\
\hline & & & Aluno 3 & 22 & 77,5 \\
\hline \multirow{3}{*}{3} & \multirow{3}{*}{27,5} & \multirow{3}{*}{25} & Aluno 1 & 20 & 72,5 \\
\hline & & & Aluno 2 & 23 & 75,5 \\
\hline & & & Aluno 3 & 15 & 67,5 \\
\hline \multirow{3}{*}{4} & \multirow{3}{*}{21} & \multirow{3}{*}{25} & Aluno 1 & 25 & 71 \\
\hline & & & Aluno 2 & 20 & 66 \\
\hline & & & Aluno 3 & 25 & 71 \\
\hline \multirow{3}{*}{5} & \multirow{3}{*}{33} & \multirow{3}{*}{25} & Aluno 1 & 25 & 83 \\
\hline & & & Aluno 2 & 24 & 82 \\
\hline & & & Aluno 3 & 24 & 82 \\
\hline \multirow{3}{*}{6} & \multirow{3}{*}{20} & \multirow{3}{*}{25} & Aluno 1 & 20 & 65 \\
\hline & & & Aluno 2 & 23 & 68 \\
\hline & & & Aluno 3 & 20 & 65 \\
\hline \multirow{3}{*}{7} & \multirow{3}{*}{22} & \multirow{3}{*}{25} & Aluno 1 & 18 & 65 \\
\hline & & & Aluno 2 & 18 & 65 \\
\hline & & & Aluno 3 & 20 & 67 \\
\hline
\end{tabular}

Entendemos que as ações fomentadas nesta intervenção pedagógica, concedendo direcionamento e liberdade aos alunos para desenvolverem suas metodologias frente ao desafio de se trabalhar com a reação do $\mathrm{S}_{2} \mathrm{O}_{3}{ }^{2-}$ em meio ácido, 
permitiu aos alunos serem os protagonistas em sala de aula. Deve-se destacar a intensa colaboração entre os grupos de forma que os alunos com metodologias já estabelecidas auxiliaram outros grupos na resolução do problema proposto. Neste sentindo, este trabalho buscou dar ênfase ao processo de aprendizagem do aluno (MAGEDANZ; HEBERT; SILVA, 2016), alterando a prática de uma educação bancária (FREIRE, 1987, p. 33) ainda presente nas salas de aula no ensino de ciências.

Ainda que os resultados demonstrem que apenas $28,5 \%$ dos grupos de alunos apresentaram aproveitamento igual ou superior a $60 \%$ da pontuação máxima possível para o relatório, entendemos que os alunos são o núcleo do processo educativo (MAGEDANZ; HERBERT; SILVA, 2016), e faz parte do processo de aprendizagem os acertos dos percursos escolhidos pelos alunos que não são adequados à prática realizada no laboratório. Neste sentindo, a intervenção pedagógica possibilitou aos alunos estabelecerem parâmetros para a tomada de decisão de quando a reação entre - $\mathrm{S}_{2} \mathrm{O}_{3}{ }^{2-}$ com $\mathrm{O}_{2} \mathrm{H}_{2} \mathrm{SO}_{4}$ havia ocorrido, bem com, permitiu que metodologias experimentais fossem elaboradas para responder às perguntas apresentadas no início do experimento. A grande deficiência dos estudantes recaiu na dificuldade em estabelecer um raciocínio lógico matemático que os permitisse identificar a ordem da reação, o tempo de meia vida do $\mathrm{S}_{2} \mathrm{O}_{3}{ }^{2-}$ e a concentração de $\mathrm{S}_{2} \mathrm{O}_{3}{ }^{2-}$ de uma amostra desconhecida. Algumas perguntas foram típicas dos alunos nesta fase da pesquisa como: "...como vou estabelecer a proporcionalidade entre o tempo decorrido para a turvação, a concentração inicial do reagente e a ordem de reação?...", ou "...como determinar a velocidade da reação a partir da medida do tempo de turvação?...", ou "...como faz para fazer contas com potência?...", ou ainda "...como faço operações utilizando o logaritmo de um número?...". São resultados que refletem a deficiência dos alunos em matemática básica, muito em razão dos múltiplos fatores que permeia as práticas pedagógicas presentes na sala de aula (RODRIGUES; RIBEIRO, 2018). 


\section{CONSIDERAÇÕES FINAIS}

Esta pesquisa teve o intuito de realizar uma intervenção pedagógica no ensino de cinética química buscando avaliar se a metodologia investigativa propiciaria aos alunos habilidades investigativas e reflexivas sobre os fatos observados em uma reação química. Podemos afirmar que em termos metodológicos de ensino, a intervenção pedagógica mostrou que os alunos estão acostumados a realizar as atividades laboratoriais com roteiros predeterminados. Deve-se destacar que a metodologia investigativa utilizada neste trabalho exigiu dos alunos uma conexão do pensar com o fazer estabelecendo um desafio nada fácil de ser vencido pelos estudantes. Sendo assim, as etapas propostas para a execução da intervenção pedagógica, envolvendo a identificação do nível de conhecimento dos estudantes participantes desta pesquisa, a etapa das aulas dialogadas, e a etapa de desenvolvimento de metodologia a ser realizar no laboratório, foram essenciais para concretização deste trabalho.

A metodologia investigativa mostrou-se desafiante aos estudantes que apresentaram muita dificuldade para elaborar um procedimento experimental que pudesse ser utilizado na resolução de um grupo de questões-problemas. Basicamente, esta dificuldade esteve atrelada a deficiência em conceitos básicos matemáticos, bem como, a ausência de conhecimentos básicos de derivada e integral. Tal deficiência, somado ao cansaço diário do trabalho, reduziu o interesse e a concentração dos alunos durante as explicações em sala de aula, dificultando o processo de ensino aprendizagem do conteúdo de cinética química.

Ainda que se tenha estabelecido conexão do conteúdo de cinética química com assuntos relacionados ao movimento CTSA num contexto sóciocientífico inclusive com uma participação bastante expressiva dos alunos envolvendo relatos que aproximaram a cinética à vida cotidiana do estudante, não se conseguiu um retorno satisfatório dos alunos quando Ihes foi solicitado exemplos de influência da cinética na sua vida diária, 
demonstrando que o ensino tradicional de ciências acrescido da menção ao conteúdo de CTSA, pode até tornar as aulas mais interessantes e motivacionais, mas não é suficiente para que ocorra a plena conexão do assunto por parte dos alunos. Vivenciamos nesta pesquisa que de fato, a incorporação eventual ou sistemática do conteúdo CTSA ao conteúdo programático do curso de licenciatura, conforme diz Batista (2014), pode favorecer um processo de ensino aprendizagem mais eficiente deste assunto relevante pelos alunos.

Este trabalho, também, demonstrou que a metodologia investigativa utilizada permitiu aos alunos desenvolver a habilidade de observação e reflexão sobre a ocorrência de uma reação química. No entanto, a ausência do conceito matemático de derivada dificultou aos alunos associar o conceito de velocidade instantânea com a identificação da ocorrência da reação, refletindo em cálculos equivocados da ordem e da Lei de velocidade da reação estudada.

Ainda que a metodologia investigativa favoreça a interação e comunicação entre os pares, auxiliando no estabelecimento de uma metodologia experimental a ser aplicada por cada grupo para responder aos questionamentos relativos a reação de tiossulfato em meio ácido, houve grupos que não conseguiram estabelecer uma metodologia adequada para quantificar a substância em uma amostra desconhecida, ainda que intervenções do professor pesquisador tenham sido realizadas.

A metodologia adotada neste trabalho conseguiu abordar o tema geração de resíduo nos laboratórios, induzindo os alunos em suas metodologias a utilizarem pequenas quantidades de reagentes. Tal prática traz ao ambiente educacional a discussão sobre a geração de resíduo laboratorial, qualificando os alunos a trabalharem com quantidades suficientes de reagentes para se atingir os mesmos resultados que seriam atingidos com grandes quantidades, além de associar a 
intervenção pedagógica às influências da cinética química junto às questões ambientais.

A intervenção também sugere a necessidade de adequações no projeto pedagógico do curso de Licenciatura em Química de forma que a disciplina de Cálculo I possa ser ministrada antes da disciplina de Química Geral II, objetivando capacitar os estudantes para que possam ter mais domínio das peculiaridades do conteúdo de cinética química frente aos problemas que podem ser encontrados numa reação química. Um estudo semelhante seria interessante em outra turma na qual fosse trabalhado com antecedência os conceitos matemáticos necessários a uma maior autonomia do estudante, pois dessa forma poderíamos esperar resultados mais promissores da aplicação da metodologia investigativa no ensino e aprendizagem do conteúdo de cinética química.

Entendemos que a metodologia aplicada neste estudo permitiu a construção do conhecimento, do pensamento crítico e reflexivo dos estudantes que foram protagonistas do seu aprendizado, conduzindo a uma prática docente em que é necessário um olhar diferenciado a cada aluno. Para nós pesquisadores, este trabalho propiciou momentos de várias aprendizagens tanto para o nosso desenvolvimento profissional como para nosso trabalho de formadores de professores. 


\section{REFERÊNCIAS}

AINKEHEAD, Glen S.. Science education for everyday life: evidence-based practice. New York: Teachers College Press. 2006.

ATKINS, Peter; DE PAULA, Júlio. Físico-Química, volume 2. 10. ed. Rio de Janeiro: LTC. 2018.

BARROW, Lloyd H.. A brief history of inquiry: from Dewey to Standards. Journal of Science Teacher Education, V. 17, N. 3, 2006.

BATISTA, Rivana Souza. Contribuintes das práticas pedagógicas colaborativas produzidas com temas sociocientíficos no PIBID de química. 2014. 56 f. Dissertação (mestrado) - Instituto Federal do Espírito Santo, Programa de Pós-Graduação em Educação em Ciências e Matemática, Espírito Santo. 2014.

DE ANDRADE, Antonio Carlos; DINIZ, Leonardo Gabriel; CAMPOS, Júlio César Costa. Uma metodologia de ensino para disciplinas de laboratório didático. Revista Docência do Ensino Superior. V. 1, 2011.

FERREIRA, Denise Helena L.; BRUMATTI, Raquel N. M.. Dificuldades em matemática em um curso de engenharia elétrica. Horizontes. V. 57, N. 1, 2009.

FERREIRA, Luiz Henrique; HARTWIG, Dácio Rodney; DE OLIVEIRA, Ricardo Castro. Ensino experimental de química: uma abordagem investigativa contextualizada. Química Nova. V. 32, N. 2, 2010.

FREIRE, Paulo. Pedagogia do oprimido. 17. ed. Rio de Janeiro: Paz e Terra. 1987.

GIORDAN, Marcelo. O papel da experimentação no ensino de ciências. Química Nova na Escola. V. 10, 1999.

GIL PEREZ, D.; VALDES CASTRO, P. La orientación de las prácticas de laboratorio como investigación: un ejemplo ilustrativo. Enseñanza de las cienciasl. V. 14, N. 2, 1996.

LOPES, Jonatha Alves. O ensino de cinética química na perspectiva CTSA na educação básica. Estudo de caso. Campina Grande: UEPB. 2013. 8-9 p. Trabalho de conclusão de curso (Graduação em Química) - Universidade Estadual da Paraíba, Centro de Ciências e Tecnologias. 2013.

LUCKESI, Cipriano Carlos. Filosofia da Educação. São Paulo: Cortez. 53p. 1994.

LUCKESI, Cipriano Carlos. Avaliação da Aprendizagem Escolar; estudos e proposições. 17. ed., São Paulo: Cortez. 2005.

MADAM, R. L.; TULI, G. D.. Oxides and Oxy-acids of sulphur. In: Inorganic Chemistry: questions and answers. New Delhi: S. Chand. 301 p. 2007. 
MAGEDANZ, Adriana; HEBERT, Jane; SILVA, Maria Cristina de Almeida. Propostas de abordagens por meio de metodologias ativas no ensino superior. Revista Destaques Acadêmicos. V. 8, N. 4, 2016.

MARCONDES, Maria Eunice Ribeiro; CARMO, Miriam P. do; SUART, Rita C.; DA SILVA, Erivanildo L.; SOUZA, Fábio L.; SANTOS JR, João B.; AKAHOSHI, Luciane H.. Materiais instrucionais numa perspectiva CTSA: uma análise de unidades didáticas produzidas por professores de química em formação continuada. Investigações em Ensino de Ciências. V. 14, N. 2, 2009.

MARTORANO, Simone Alves de Assis. As concepções de ciência dos livros didáticos de química, dirigidos ao ensino médio, no tratamento da cinética química no período de 1929 a 2004. 2007. Dissertação (Mestrado em Ensino de Ciências) - Instituto de Química, Universidade de São Paulo. 2007.

MARTORANO, Simone Alves de Assis; MARCONDES, Maria Eunice Ribeiro. As concepções de ciência dos livros didáticos de química, dirigidos ao ensino médio, no tratamento da cinética química no período de 1929 a 2004. Investigações em Ensino de Ciências. V. 14, N. 3, 2009.

DE OLIVEIRA, Maria da Glória Medici; PAIVA, Maria Auxiliadora Vilela. Proeja Classroom as a Teacher Training Space. SBEM: Revista RIPEM. V. 2, 2018.

PADILHA, Paulo Roberto. Planejamento dialógico: como construir o projeto políticopedagógico da escola. São Paulo: Ed. Cortez. 2001.

RIBEIRO, Júlio Wilson Ribeiro; DE LIMA, Luciana; VALENTE, José Armando; LITTO, Fredric Michael; GÓES, Ubaldo Tonar T.; COSTA, Mário Jorge N.. Integração das tecnologias e currículo: mapeamento cognitivo e transdisciplinaridade em disciplinas de cursos de licenciatura presenciais. In: MORAES, Silva Elisabeth; ALBUQUERQUE, Luiz Botelho. Estudos em currículo e ensino: concepções e práticas. Campinas: Mercado de Letras. p. 135-161. 2014.

RODRIGUES, Paulo Marcelo Silva; RIBEIRO, Júlio Wilson. Possibilidades de integração das teorias de Philip Phenix e David Ausubel para promover o mapeamento de conteúdos de ciências e matemática numa abordagem interdisciplinar. In: BORGESNOJOSA, Diva Maria; DE LIMA, Isaías Batista; RIBEIRO, Júlio Wilson. Interdisciplinaridade no ensino de Ciências e Matemática. Fortaleza: Imprensa Universitária UFC. p. 45-65. 2018.

RUSSELL, John. B.. Química Geral Vol. 1. 2. Ed. São Paulo: Pearson. 1994.

SALESSE, Lucilene Zacharias; BARICATTI, Reinaldo Aparecido. O currículo escolar e a experimentação na busca de uma alfabetização científica no ensino da química de qualidade e com utilidade no ensino médio. 2007. Disponível em: 
$<$ http://www.gestaoescolar.diaadia.pr.gov.br/modules/conteudo/conteudo.php?cont eudo=136>. Acesso em: 27 jan 2018.

SCHWAHN, Maria Cristina Aguirre.; OAIGEN, Edson Roberto. O uso do laboratório de ensino de química como ferramenta: investigando as concepções de licenciados em química sobre o predizer, observar, explicar (POE). Acta Scientiae. V. 10, N. 2, 2008.

SOUZA, Isis Lidiane Norato; BORGES, Francielle da Silva. A experimentação investigativa no ensino de química: reflexões de práticas experimentais a partir do PIBID. In: CONGRESSO NACIONAL DE EDUCAÇÃO, 9, 2013, Curitiba. Anais do XI Congresso Nacional de Educação. Curitiba: EDUCERE, 2013. V. 1, p.13929-13941.

ZÔMPERO, Andreia Freitas; LABURÚ, Carlos Eduardo. Atividades investigativas no ensino de ciências: aspectos históricos e diferentes abordagens. Ensaio Pesquisa em Educação em Ciências. V. 13, N. 3, 2011. 